Supplemental Table 1

\title{
Human genome-wide
}

\begin{tabular}{|l|l|l|l|l|}
\hline \multicolumn{1}{|c|}{ Library } & \multicolumn{1}{|c|}{ Type } & gRNAS & $\begin{array}{c}\text { gRNAs } \\
\text { per gene }\end{array}$ & \multicolumn{1}{|c|}{$\begin{array}{c}\text { Addgene catalog } \\
\text { number }\end{array}$} \\
\hline $\begin{array}{l}\text { Activity-optimized genome- } \\
\text { wide library }\end{array}$ & Knockout & 187,535 & 10 & 1000000100 \\
\hline Broad GPP Brunello & Knockout & 76,441 & 4 & $\begin{array}{l}73179 \\
73178\end{array}$ \\
\hline Gattinara & Knockout & 40,964 & 2 & 136986 \\
\hline Human GeCKO v2 & Knockout & 123,411 & 6 & 1000000048 \\
\hline $\begin{array}{l}\text { Human genome-wide library } \\
\text { v1 }\end{array}$ & Knockout & 77,406 & 4 & 69763 \\
\hline $\begin{array}{l}\text { Human improved genome- } \\
\text { wide library v1 }\end{array}$ & Knockout & 90,709 & 5 & 67989 \\
\hline $\begin{array}{l}\text { Reduced Double -RNA } \\
\text { Library }\end{array}$ & Knockout & 59,576 & 3 & 137999 \\
\hline sgRNA iBAR library & Knockout & 58,630 & 3 & 140633 \\
\hline $\begin{array}{l}\text { Mini-human AsCpf1-based } \\
\text { Library }\end{array}$ & Knockout & 17,032 \\
arrays & $3-4$ & 130630 \\
\hline $\begin{array}{l}\text { Toronto KnockOut - Version } \\
1\end{array}$ & Knockout & 176,500 & 12 & 1000000069 \\
\hline $\begin{array}{l}\text { Toronto KnockOut - Version } \\
3\end{array}$ & Knockout & 70,948 & 4 & 90294 \\
\hline $\begin{array}{l}\text { Two plasmid human activity- } \\
\text { optimized genome-wide } \\
\text { library }\end{array}$ & Knockout & 187,536 & 10 & 10000000095 \\
\hline $\begin{array}{l}\text { Broad GPP Calabrese p65- } \\
\text { HSF }\end{array}$ & Activation & 113,238 & 6 & $\begin{array}{l}92379 \\
92380\end{array}$ \\
\hline CRISPRa-v2 & Activation & 104,540 & 5 & 83978 \\
\hline IncRNA Activation Library & Activation & 209,080 & 10 & 1000000091 \\
\hline SAM v1 - 3 plasmid system & Activation & 70,290 & 10 & 1000000106 \\
\hline SAM v2 - 2 plasmid system & Activation & 70,290 & 3 & 1000000057 \\
\hline Broad GPP Dolcetto & Inhibition & 113,526 & 6 & 1000000074 \\
\hline $\begin{array}{l}\text { CRISPRi-v2 } \\
\text { Inhibition }\end{array}$ & 104,535 & 5 & 92385 \\
92386 \\
\hline
\end{tabular}


Mouse genome-wide

\begin{tabular}{|c|c|c|c|c|}
\hline Library & Type & gRNAS & $\begin{array}{l}\text { gRNAs } \\
\text { per gene }\end{array}$ & $\begin{array}{c}\text { Addgene catalog } \\
\text { number }\end{array}$ \\
\hline Broad GPP Brie & Knockout & 78,637 & 4 & $\begin{array}{l}73632 \\
73633\end{array}$ \\
\hline Gouda & Knockout & 44,155 & 2 & 136987 \\
\hline Mouse GeCKO v2 & Knockout & 130,209 & 6 & $\begin{array}{l}1000000052 \\
1000000053\end{array}$ \\
\hline $\begin{array}{l}\text { Mouse improved genome- } \\
\text { wide library v1 }\end{array}$ & Knockout & 90,230 & 5 & 67988 \\
\hline $\begin{array}{l}\text { Mouse Toronto KnockOut } \\
(\mathrm{mTKO})\end{array}$ & Knockout & 19,463 & $\sim 5$ & $\begin{array}{l}159392 \\
159393 \\
\end{array}$ \\
\hline Retroviral Knockout Library & Knockout & 90,230 & 5 & 104861 \\
\hline $\begin{array}{l}\text { Two plasmid mouse } \\
\text { activity-optimized genome- } \\
\text { wide library }\end{array}$ & Knockout & 188,509 & 10 & 1000000096 \\
\hline $\begin{array}{l}\text { Broad GPP Caprano p65- } \\
\text { HSF }\end{array}$ & Activation & 134,076 & 6 & $\begin{array}{l}92383 \\
92384 \\
\end{array}$ \\
\hline CRISPRa-v2 & Activation & $\begin{array}{l}107,105 \\
214,210\end{array}$ & $\begin{array}{l}5 \\
10 \\
\end{array}$ & $\begin{array}{l}83996 \\
1000000093\end{array}$ \\
\hline SAM v1 - 3 plasmid system & Activation & 69,716 & 3 & 1000000075 \\
\hline Broad GPP Dolomiti & Inhibition & 134,560 & 6 & $\begin{array}{l}104090 \\
104091\end{array}$ \\
\hline CRISPRi-v2 & Inhibition & $\begin{array}{l}107,415 \\
214,830 \\
\end{array}$ & $\begin{array}{l}5 \\
10 \\
\end{array}$ & $\begin{array}{l}83987 \\
1000000092 \\
\end{array}$ \\
\hline
\end{tabular}

\section{Human sub-library}

\begin{tabular}{|l|l|l|l|l|}
\hline \multicolumn{1}{|c|}{ Library } & \multicolumn{1}{|c|}{ Type } & gRNAS & $\begin{array}{c}\text { gRNAs } \\
\text { per gene }\end{array}$ & \multicolumn{1}{c|}{$\begin{array}{c}\text { Addgene catalog } \\
\text { number }\end{array}$} \\
\hline Bassik Knockout Library & Knockout & Varies & 10 & $101926-101934$ \\
\hline $\begin{array}{l}\text { Bradley Human CRISPR Poison } \\
\text { Exon Knockout Library }\end{array}$ & Knockout & 9,508 & $\begin{array}{l}\sim 9 \text { pairs/ } \\
\text { exon }\end{array}$ & 138084 \\
\hline Broad GPP kinome Brunello & Knockout & 3,052 & 4 & $\begin{array}{l}7531475315 \\
7531275313\end{array}$ \\
\hline $\begin{array}{l}\text { Enriched subpools (kinase, } \\
\text { nuclear, ribosomal, cell cycle) }\end{array}$ & Knockout & Varies & 10 & $51043-51048$ \\
\hline
\end{tabular}




\begin{tabular}{|l|l|l|l|l|}
\hline $\begin{array}{l}\text { Focused Ras Synthetic Lethal } \\
\text { Human CRISPR Knockout } \\
\text { Library }\end{array}$ & Knockout & 6,661 & 50 & 92352 \\
\hline Epigenetic Knockout Library & Knockout & 20,051 & 8 & 162256 \\
\hline $\begin{array}{l}\text { Interferon-Stimulated Gene } \\
\text { Knockout Library }\end{array}$ & Knockout & 15,416 & 8 & 125753 \\
\hline $\begin{array}{l}\text { Metabolic Gene Knockout } \\
\text { Library }\end{array}$ & Knockout & 30,290 & 10 & 110066 \\
\hline $\begin{array}{l}\text { DNA Binding Domain-Focused } \\
\text { Knockout Library }\end{array}$ & Knockout & 8,658 & 6 & 123334 \\
\hline $\begin{array}{l}\text { Kinase Domain-Focused } \\
\text { Knockout Library }\end{array}$ & Knockout & 3,051 & 6 & 117725 \\
\hline $\begin{array}{l}\text { lncRNA Splicing-targeting } \\
\text { Library }\end{array}$ & Knockout & 126,773 & Varies & 119977 \\
\hline mTORC1 Focused Library & Knockout & 7,501 & 10 & 164084 \\
\hline miRNA Knockout Library & Knockout & 8,382 & $4-5$ & 112200 \\
\hline $\begin{array}{l}\text { Paired-guide RNA (pgRNA) } \\
\text { Library for Long Non-coding } \\
\text { RNAs (lncRNAs) }\end{array}$ & Knockout & 12,472 & Varies & 89640 \\
\hline SLC Knockout Library & Knockout & 2,609 & 6 & 132552 \\
\hline $\begin{array}{l}\text { Transcription Factor Knockout } \\
\text { Library }\end{array}$ & Knockout & 11,364 & $\sim 7$ & 162275 \\
\hline $\begin{array}{l}\text { Neelamegham GlycoGene } \\
\text { Library }\end{array}$ & Knockout & 3,637 & 10 & 140961 \\
\hline $\begin{array}{l}\text { RNA-Binding Protein Pooled } \\
\text { Knockout Library }\end{array}$ & Knockout & 12,472 & 10 & 141438 \\
\hline $\begin{array}{l}\text { CHyMErA Paralog \& Dual- } \\
\text { targeting hgRNA library }\end{array}$ & Knockout & 92,746 & Varies & 155199 \\
\hline $\begin{array}{l}\text { CHyMErA Exon-deletion } \\
\text { hgRNA library }\end{array}$ & Knockout & 91,948 & Varies & 155200 \\
\hline $\begin{array}{l}\text { hCRISPRa-v2 } \\
\text { Membrane Protein Activation } \\
\text { Library }\end{array}$ & Activation & 58,570 & $7-14$ & 113345 \\
\hline SLC Activation Library & Activation & 3,342 & 6 & 132561 \\
\hline $\begin{array}{l}\text { CRiNCL - Human CRISPRi } \\
\text { Non-coding Libraries }\end{array}$ & Inhibition & Varies & 10 & $86538-86550$ \\
\hline hCRISPRi-v2 & Inhibition & Varies & 5 & $83971-83977$ \\
\hline $\begin{array}{l}\text { CRISPRi titration libraries } \\
\text { Inhibition }\end{array}$ & Varies & Varies & 136478 \\
136479 \\
\hline
\end{tabular}


Mouse sub-library

\begin{tabular}{|c|c|c|c|c|}
\hline Library & Type & gRNAS & $\begin{array}{c}\text { gRNAs } \\
\text { per gene }\end{array}$ & $\begin{array}{c}\begin{array}{c}\text { Addgene catalog } \\
\text { number }\end{array} \\
\end{array}$ \\
\hline Bassik Knockout Library & Knockout & Varies & 10 & $1000000121-1000000130$ \\
\hline Broad GPP kinome Brie & Knockout & 2,852 & 4 & $\begin{array}{l}75317 \\
75316\end{array}$ \\
\hline $\begin{array}{l}\text { CRISPR/Cas9-assisted } \\
\text { Removal of Mitochondrial } \\
\text { DNA (CARM) }\end{array}$ & Knockout & 395 & N/A & 82480 \\
\hline $\begin{array}{l}\text { Cardiac Transcriptional } \\
\text { Regulators Library }\end{array}$ & Knockout & 14,671 & 6 & 138015 \\
\hline Metabolic Gene Library & Knockout & 22,909 & 8 & 160129 \\
\hline $\begin{array}{l}\text { Metastasis CRISPR- } \\
\text { Cpf1(Cas12a) Double } \\
\text { Knockout Library }\end{array}$ & Knockout & $\begin{array}{l}11,934 \\
\text { arrays }\end{array}$ & 4 & 123361 \\
\hline SLC Knockout Library & Knockout & 2,384 & 6 & 141436 \\
\hline $\begin{array}{l}\text { Tumor Suppressor Gene } \\
\text { Knockout Library }\end{array}$ & Knockout & 286 & 4 & $\begin{array}{l}113584 \\
113585\end{array}$ \\
\hline Validation (mVAL) Library & Knockout & 182 & 4 & 159391 \\
\hline mCRISPRa-v2 libraries & Activation & Varies & 5 & $83998-84004$ \\
\hline $\begin{array}{l}\text { Transcription Factor } \\
\text { Activation Library }\end{array}$ & Activation & 51,762 & 20 & 122131 \\
\hline mCRISPRi-v2 libraries & Inhibition & Varies & 5 & $83989-83995$ \\
\hline
\end{tabular}

